\title{
Diagnosis of Fat Malabsorption by Breath Tests: Just a Breeze?
}

\author{
Jutta Keller \\ Department of Internal Medicine, Israelitic Hospital, University of Hamburg, Hamburg, Germany
}

In this issue of Digestion Nakamura et al. [1] report differential fat digestion and absorption rates in patients after subtotal gastrectomy who underwent different surgical procedures for reconstruction, that is Billroth I or Roux-en-Y. Using a noninvasive breath test they show that the Billroth I procedure allows almost normal triglyceride digestion and absorption. By contrast, the Roux-en-Y procedure is associated with a $30-40 \%$ decrease in fat absorption compared with both healthy controls and patients who have undergone the Billroth I procedure.

These findings are not entirely new but rather confirm the accepted opinion that maintenance of food passage through the duodenum is of importance for efficacy of nutrient digestion and absorption in patients who have undergone subtotal gastrectomy, and that therefore the Billroth I procedure is the more physiological approach. Moreover, patient allocation to the two treatment groups appears questionable and the numbers of subjects per group are not too impressive: either Billroth I $(\mathrm{n}=17)$ or Roux-en-Y $(\mathrm{n}=14)$ was performed according to the surgeons' preferences in 31 patients overall and data obtained in these patients were compared with fat absorption rates of 15 healthy volunteers.

By contrast, Ogoshi et al. [2] examined data of more than 1,000 patients who underwent total or partial gastrectomies because of gastric cancer. They showed that duodenal food passage reconstruction was an independent prognostic factor for improved survival rate. However, retrospective studies like this do, of course, not allow a comparison of the absorption of specific nutrients. Overall, there is an astonishing paucity of experimental studies published in English that directly investigate absorption of various nutrients in patients following gastric resections [3-7]. Accordingly, the current study performed by Nakamura et al. [1] makes a significant contribution to our understanding of pathophysiological consequences of different surgical procedures for reconstruction after gastrectomy and may help to guide the choice of surgical techniques.

Another interesting aspect of this study is that the authors employ a modern technique for their measurements, that is a breath test using ${ }^{13} \mathrm{C}$-labeled lipids. This test may have diagnostic importance beyond the specific aims of this study: ${ }^{13} \mathrm{C}$-marked triglycerides are nonradioactive and can be applied safely and repeatedly, also to children and pregnant women. Breath tests using these lipids are based on the principle that intestinal triglyceride absorption requires prior hydrolysis by lipase to produce free fatty acids and monoacylglycerol. These metabolites are incorporated into micelles, absorbed, resynthesized and transported to the liver. Lipolytic hepatic enzymes subsequently release ${ }^{13} \mathrm{C}$-marked fatty acids. These undergo $\beta$-oxidation which results in formation of ${ }^{13} \mathrm{CO}_{2}$ that is absorbed into the bloodstream, transported to the lung and exhaled. The increase in ${ }^{13} \mathrm{CO}_{2}$ concentration in breath thus correlates with intestinal lipid digestion and absorption. Accordingly, breath tests based on ${ }^{13} \mathrm{C}$-labeled lipids can be used as a substitute for the unpopular direct measurement of fecal fat excretion as done by Nakamura et al. [1] in their recent study and as several other investigators did earlier $[3,8,9]$. Lipid-based ${ }^{13} \mathrm{C}$-breath tests have not only been used successfully for

\section{KARGER}

Fax +41613061234 E-Mail karger@karger.ch www.karger.com (c) 2009 S. Karger AG, Basel

0012-2823/09/0802-0095\$26.00/0

Accessible online at:

www.karger.com/dig
Jutta Keller, MD

Department of Internal Medicine, Israelitic Hospital, University of Hamburg

Orchideenstieg 14

DE-22297 Hamburg (Germany)

Tel. +49 4051125 5040, Fax +49 4051125 5045, E-Mail keller@ik-h.de 
diagnosis of fat malabsorption per se but also for monitoring of therapeutic measures $[10,11]$.

Moreover, since pancreatic lipase is mainly responsible for intestinal lipolysis, these tests may also represent modern alternatives to currently available pancreatic function tests that are badly needed. Indeed, despite astounding developments in virtually every other diagnostic field (including pancreatic imaging), pancreatic exocrine function is generally estimated today by using very much the same principles and methods as 3 decades ago. Our diagnostic armamentarium is even becoming smaller than before, since Pankreolaury ${ }^{\circledR}$ is no longer available in several countries. Moreover, direct pancreatic function tests such as the secretin and secretin-cerulein test or measurement of fecal fat excretion are so timeconsuming, expensive and/or cumbersome that they are hardly performed any longer. This leaves us with the measurement of fecal elastase- 1 that is easy to perform and, compared with fecal chymotrypsin, appears to be more sensitive and specific. However, the test only assesses enzyme concentrations, so that there are numerous false-positive results in patients with intestinal diseases and diarrhea [12-14]; mild to moderate pancreatic exocrine insufficiency cannot be diagnosed reliably [14]. Endoscopy-based modifications of the secretin or secretin-cerulein test and secretin-enhanced MRI for measurement of pancreatic exocrine function are under investigation but are not readily available and represent invasive and/or expensive procedures. In conclusion, there is an unmet need for improved pancreatic function tests that are widely available; breath tests using ${ }^{13} \mathrm{C}$-marked substrates might bridge this gap - at least partly.

The ideal pancreatic function test should be noninvasive, precise, reliable, uncomplicated and inexpensive. However, as explained above, no currently available test meets all these criteria and, to come to the point, ${ }^{13} \mathrm{C}$ breath tests do not achieve all of these goals either. They estimate pancreatic exocrine function indirectly by measuring the effect of pancreatic enzymes on digestion of their specific substrates. A large number of tests have been developed using not only a variety of ${ }^{13} \mathrm{C}$-marked triglycerides but also ${ }^{13} \mathrm{C}$-starch and ${ }^{13} \mathrm{C}$-marked proteins [15-17]. However, in pancreatic exocrine insufficiency impairment of fat digestion and absorption is usually more severe than that of other macronutrients [18], and therefore breath tests based on ${ }^{13} \mathrm{C}$-marked lipids appear to be most promising. Indeed, the occurrence of ${ }^{13} \mathrm{CO}_{2}$ in breath is directly related to duodenal pancreatic lipase activity in healthy adults $[19,20]$. But, as becomes evident from the test principle, ${ }^{13} \mathrm{CO}_{2}$ excretion also depends on other sources of lipolytic activity (gastric lipase), biliary secretion that is needed for formation of micelles, gastrointestinal transit and absorption as well as hepatic and lung function. This means that the test cannot be $100 \%$ specific for pancreatic exocrine insufficiency but may give 'false-positive' pathological results in all diseases that are associated with fat malabsorption as well as in severe liver or lung disease and gastroparesis. The test is not $100 \%$ sensitive either, particularly not in mild exocrine insufficiency. Löser et al. [21] demonstrated that the ${ }^{13} \mathrm{C}$-mixed triglyceride breath test identifies all patients with markedly decreased duodenal lipase output and steatorrhea corresponding to severe exocrine insufficiency. By contrast, sensitivity was only about $50 \%$ in patients with mild or 'compensated' impairment of pancreatic exocrine function defined as subnormal lipase output but normal fecal fat excretion.

However, it has to be considered that fecal fat excretion occurs as the net result of all intestinal digestive and absorptive processes. It will therefore only give pathological results if all adaptive mechanisms are exhausted. The enormous reserve capacity of the pancreas [22] explains why steatorrhea usually is a late event in the natural history of chronic pancreatitis, occurring 10-20 years after its onset [23]. In this context, the ${ }^{13} \mathrm{C}$-mixed triglyceride breath test offers several advantages, at least theoretically: ${ }^{13} \mathrm{CO}_{2}$ excretion following administration of ${ }^{13} \mathrm{C}$-mixed triglycerides gives a time course of digestive processes and may thus reflect a shift of fat digestion and absorption to more distal parts of the small intestine. This has not been investigated thoroughly, so far. Moreover, maintenance of a diet with a high and defined fat content for 3 days as necessary for reliable measurement of fecal fat excretion is often difficult to achieve, particularly in patients with abdominal complaints. By contrast, the lipid content of the single test meal needed for the breath test can be increased fairly easily. This might overrule 'compensated' pancreatic exocrine insufficiency and thereby enhance sensitivity of the test procedure. Indeed, our preliminary experience with this test using a higher fat dose than Löser et al. [21] did and with strict avoidance of physical activity (to keep $\mathrm{CO}_{2}$ production rate stable [24]) shows a high sensitivity and specificity compared with the secretin-cerulein test even in patients with mildly impaired pancreatic exocrine function (unpubl. results).

So far, breath tests using ${ }^{13} \mathrm{C}$-mixed triglycerides or other lipids marked with ${ }^{13} \mathrm{C}$ have remained nonstandardized. This does not only refer to the optimum dose of tracer and fat or conditions of test performance, but even the term

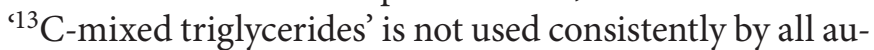


thors. The term originally means triglycerides with a mixture of long- and medium-chain fatty acids, that is two molecules of long chain fatty acids at the Sn- 1 and -3 positions and a marked medium chain fatty acid at the Sn-2 position [typically 1,3 -distearyl-2 $\left({ }^{13} \mathrm{C}\right.$-octanoyl $)$ glycerol] $[19,25]$. Nakamura et al. [1] incorrectly use the term for describing a mixture of triglycerides with naturally occurring long-chain fatty acids that are uniformly labeled with ${ }^{13} \mathrm{C}$. Apart from the irritating diversity of wording, this differentiation is of importance because ${ }^{13} \mathrm{C}$-mixed triglycerides offer several advantages over other lipid substrates, for instance they allow a shorter test duration [26].

Taken together, lipid-based ${ }^{13} \mathrm{C}$-breath tests, particularly the ${ }^{13} \mathrm{C}$-mixed triglyceride breath test, can already be used as a substitute for fecal fat analysis and as pancreatic function tests that reliably detect severe pancreatic exocrine insufficiency. However, in order to take advantage of the full potential of these tests, further standardization and improvement are warranted with respect to the choice and dose of the tracer, nutrient dose, composition of the test meal, conditions of performance (resting) and identification of the optimal parameters for analysis that may differ for evaluation of pancreatic exocrine function and fat absorption. The efforts that are still necessary to achieve these goals appear justified - not only because we lack better alternatives but also because these tests are noninvasive, comparably inexpensive, simple and safe.

\section{References}

1 Nakamura H, Murakami Y, Morifuji M, Uemura K, Hayashidani Y, Sudo T, Ohge H, Sueda T: Analysis of fat digestive and absorptive function after subtotal gastrectomy by a ${ }^{13} \mathrm{C}$-labeled mixed triglyceride breath test. Digestion, in press.

-2 Ogoshi K, Okamoto Y, Nabeshima K, Morita M, Nakamura K, Iwata K, Soeda J, Kondoh Y, Makuuchi H: Focus on the conditions of resection and reconstruction in gastric cancer. What extent of resection and what kind of reconstruction provide the best outcomes for gastric cancer patients? Digestion 2005; 71:213-224

3 Takase M, Sumiyama Y, Nagao J: Quantitative evaluation of reconstruction methods after gastrectomy using a new type of examination: digestion and absorption test with stable isotope ${ }^{13} \mathrm{C}$-labeled lipid compound. Gastric Cancer 2003;6:134-141.

4 Armbrecht U, Lundell L, Stockbrugger RW: The benefit of pancreatic enzyme substitution after total gastrectomy. Aliment Pharmacol Ther 1988;2:493-500.

5 Keynes WM, Penfold WA: Study of fat absorption after gastric surgery using a fatty test metal. Ann Surg 1971;173:363-371.

-6 Beno I, Bucko A, Chorvathova V, Babala J: Absorption of d-xylose and fat and histological changes of the small intestine in patients after partial gastrectomy. Digestion 1970;3:97-104.

-7 Poth EJ, Smith LB: Digestion and absorption following gastrectomy using reversed jejunal segments: follow up of 50 cases. Ann Surg 1966;163:957-960.

-8 Watkins JB, Schoeller DA, Klein PD, Ott DG, Newcomer AD, Hofmann AF: ${ }^{13} \mathrm{C}$-trioctanoin: a nonradioactive breath test to detect fat malabsorption. J Lab Clin Med 1977;90: 422-430.

\9 Miyakawa S, Hayakawa M, Horiguchi A, Mizuno K, Ishihara S, Niwamoto N, Miura $\mathrm{K}$ : Estimation of fat absorption with the ${ }^{13} \mathrm{C}$ trioctanoin breath test after pancreatoduo- denectomy or pancreatic head resection. World J Surg 1996;20:1024-1028.

10 Braden B, Picard H, Caspary WF, Posselt HG, Lembcke B: Monitoring pancreatin supplementation in cystic fibrosis patients with the ${ }^{13} \mathrm{C}$-hiolein breath test: evidence for normalized fat assimilation with high dose pancreatin therapy. Z Gastroenterol 1997;35: 123-129.

11 Dominguez-Munoz JE, Iglesias-Garcia J, Vilarino-Insua $M$, Iglesias-Rey $M:{ }^{13} \mathrm{C}$ mixed triglyceride breath test to assess oral enzyme substitution therapy in patients with chronic pancreatitis. Clin Gastroenterol Hepatol 2007;5:484-488.

12 Lankisch PG, Schmidt I: Fecal elastase 1 is not the indirect pancreatic function test we have been waiting for. Dig Dis Sci 2000;45: 166-167.

13 Luth S, Teyssen S, Forssmann K, Kolbel C, Krummenauer F, Singer MV: Fecal elastase1 determination: 'gold standard' of indirect pancreatic function tests? Scand J Gastroenterol 2001;36:1092-1099.

14 Siegmund E, Lohr JM, Schuff-Werner P: The diagnostic validity of non-invasive pancreatic function tests - a meta-analysis (in German). Z Gastroenterol 2004;42:1117-1128.

15 Löser C, Mollgaard A, Aygen S, Hennemann $\mathrm{O}$, Folsch UR: ${ }^{13} \mathrm{C}$-starch breath test - comparative clinical evaluation of an indirect pancreatic function test. Z Gastroenterol 1997;35:187-194.

-16 Evenepoel P, Hiele M, Geypens B, Geboes KP, Rutgeerts P, Ghoos Y: ${ }^{13} \mathrm{C}$-egg white breath test: a non-invasive test of pancreatic trypsin activity in the small intestine. Gut 2000;46:52-57.

17 Ishii Y, Kohno T, Ito A, Suzuki S, Kohno T, Takayama T, Asai S: Evaluation of pancreatic exocrine secretion using ${ }^{13} \mathrm{C}$-dipeptide (benzoyl-L-tyrosyl-[1-(13)C]alanine) breath test: focusing on pancreatoduodenectomy cases. Pancreas 2007;35:313-319.
18 Keller J, Layer P: Human pancreatic exocrine response to nutrients in health and disease. Gut 2005;54(suppl 6):vi1-vi28.

19 Vantrappen GR, Rutgeerts PJ, Ghoos YF, Hiele MI: Mixed triglyceride breath test: a noninvasive test of pancreatic lipase activity in the duodenum. Gastroenterology 1989;96: 1126-1134

20 Keller J, Jahr C, Brueckel S, Gresens A, Layer $\mathrm{P}$ : The ${ }^{13} \mathrm{C}$-mixed triglyceride breath test quantifies pancreatic enzyme output in healthy volunteers. Gut 2002;51:1.

21 Löser C, Brauer C, Aygen S, Hennemann O, Folsch UR: Comparative clinical evaluation of the ${ }^{13} \mathrm{C}$-mixed triglyceride breath test as an indirect pancreatic function test. Scand J Gastroenterol 1998;33:327-334.

22 DiMagno EP, Go VL, Summerskill WH: Relations between pancreatic enzyme outputs and malabsorption in severe pancreatic insufficiency. N Engl J Med 1973;288:813815.

23 Layer P, Yamamoto H, Kalthoff L, Clain JE, Bakken LJ, DiMagno EP: The different courses of early- and late-onset idiopathic and alcoholic chronic pancreatitis. Gastroenterology 1994;107:1481-1487.

24 Kalivianakis M, Verkade HJ, Stellaard F, van der Were M, Elzinga $\mathrm{H}$, Vonk RJ: The ${ }^{13} \mathrm{C}$ mixed triglyceride breath test in healthy adults: determinants of the ${ }^{13} \mathrm{CO}_{2}$ response. Eur J Clin Invest 1997;27:434-442.

25 Ghoos YF, Vantrappen GR, Rutgeerts PJ, Schurmans PC: A mixed-triglyceride breath test for intraluminal fat digestive activity. Digestion 1981;22:239-247.

26 Keller J, Franke A, Storr M, Wiedbrauck F, Schirra J: Clinically relevant breath tests in gastroenterological diagnostics - recommendations of the German society for neurogastroenterology and motility as well as the German society for digestive and metabolic diseases. Z Gastroenterol 2005;43: 1071-1090. 